\title{
Complexities of Protein Therapeutics and Immunogenicity
}

\section{Alok Bandyopadhyay*}

RAC, AB Consulting, Lansdale, Pennsylvania 19446, USA

\begin{abstract}
Biopharmaceuticals like monoclonal antibodies are widely used in clinical medicine for various therapies e.g. cancer, inflammatory and autoimmune diseases. Immunogenicity is one of the issues for safety. Such undesired immunogenicity can also limit the use of biopharmaceuticals, particularly for the treatment of chronic diseases that necessitate repeated treatments over long period. Assessment of immunogenicity is an important component of drug safety evaluation, which is presently performed by estimating risk factors. Risk based approach considers both probability of induction of immune response and expected clinical consequences. A combination of the two may result in high, medium or low risk levels and will depend on the product, patient and treatment related characteristics. Well engineered cells, well designed formulation coupled with good manufacturing scheme may sometimes reduce some of the extrinsic and intrinsic factors and increase the stability of drug product. One of the proposal for remedies is to purify the drug product to homogeneity or near homogeneity retaining its stability and functional activity. On the other hand, quite a few biosimilar drugs, which are supposed to be economical version of branded biotherapeutics, is expected to be in the market in next several years. Unfortunately, biosimilar manufacturing is often different from the brand name drug due to variation in manufacturing processes. As a result, such variations may trigger unwanted immunogenicity. Risk based approach, like branded drug, is more likely be required for drug development of therapeutic proteins for evaluation of immunogenicity followed by a development plan for risk mitigation.
\end{abstract}

\section{Introduction}

Protein therapeutics, including monoclonal antibodies and cytokines, have become mainstream treatments in a number of clinical settings starting from pain control, cardiovascular to oncology Recombinant analogs of growth factors e.g.Type1 interferon's (IFNs) or interleukin-2(IL-2), insulin, or erythropoietin (EPO) are also used in the therapy. The critical part of drug development process is to accurately assess drug exposure to determine the bioavailability of the drug. Immunogenicity is one of the issues for safety. On challenge the drug induces anti-drug antibodies (ADA) which may be either sustaining, or clearing or neutralizing antibody $(\mathrm{Ab})$. Sustaining Abs prolong the halflife by protecting it from normal clearance. In contrast clearing Abs more quickly decreases drug concentration below the therapeutic levels or removes the drug from circulation. The neutralizing Abs abrogate a drug's therapeutic effect and potentially induce serious side-effects. All of these clearing processes can affect pharmacokinetics (PK), pharmacodynamics (PD), and bioavailability analyses which in some cases minimize the potency of the drug on risk based approach and can also limit the use of these drug products [1-10]. On the other hand, repeated injection of these drug products to human in different physical condition can result in a break in immune tolerance to self-antigens leading to the product of adverse event response and sometimes immune complex disease or allergic reactions. Assessment of immunogenicity is an important component of drug safety evaluation, which is presently performed by estimating risk factors. Risk based approach considers both probability of induction of immune response and expected clinical consequences. A combination of the two may result in high, medium or low risk levels and will depend on the product, patient and treatment related characteristics. Risk based evaluation was described in several publications [4-8].

On the other hand, several biosimilar drugs, which are supposed to be the economical version of branded biotherapeutics, will probably be getting market approval in next few years. Unfortunately, biosimilar manufacturing is often different from the brand name drug due to variances in preparation starting from raw materials to finalized products. As a result, such variations may trigger unwanted immunogenicity. It is the purpose of this review to outline the current knowledge of immunogenicity related to biotheapeutics. Further it will discuss about risk assessment plan and strategies for risk mitigation.

\section{Factors Influencing Immunogenicity}

Drug development processes contribute some extrinsic and intrinsic factors, which relates to immunogenicity [11-17]. The factors are categorized as product related, process related and patient related. Some of these factors are described here in brief.

\section{Product related}

There are several product related factors which can influence immunogenicity. Most of these factors are mainly protein structure related. They are evolved through formulation, storage, or packaging. Some of these factors are summarized in the following:

$\checkmark$ Drugs undergo oxidation, deamination, and deamination resulting in production of degradation products which can influence or trigger immunogenicity. Similarly drug molecules form aggregates through intermolecular bonding and are subjected to trigger immunogenicity. It has been suggested that aggregated proteins form repetitive arrays that can lead to efficient cross-linking of B-cell receptors, leading to B-cell activation in the absence of T-cell helper, thereby resulting in a break in immune tolerance to self-proteins [16-18].

$\checkmark \quad$ It was customary approach to add exogenous protein to drug product during its manufacturing processes for stabilization. The introduction of such exogenous protein has the potential

*Corresponding author: Alok Bandyopadhyay, RAC, AB Consulting, Lansdale, Pennsylvania 19446, USA, E-mail: akbandy@gmail.com

Received December 19, 2014; Accepted May 06, 2015; Published May 11, 2015

Citation: Bandyopadhyay A (2015) Complexities of Protein Therapeutics and Immunogenicity. J Bioanal Biomed 7: 070-074. doi:10.4172/1948-593X.1000126

Copyright: (c) 2015 Bandyopadhyay A. This is an open-access article distributed under the terms of the Creative Commons Attribution License, which permits unrestricted use, distribution, and reproduction in any medium, provided the original author and source are credited. 
to elicit antibodies. Repeated administration of this drug product may cause a break in immune tolerance leading to the development of an immune response and so EU has adopted regulations prohibiting the addition of exogenous proteins [19]. For anemia drug Eprex, exogenous protein was replaced by polysorbate 80 and glyine to comply with EU regulation. Yet, an increase in the incidence of pure red cell aplasia was observed. So the Manufacturer modified the storage and handling protocols including container closure system to curve this risk [20-22].

$\checkmark$ Protein misfolding, an intrinsic property of proteins, and other unrelated factors have been described to influence biopharmaceutical immunogenicity. For instance, Metalcatalyzed oxidation of rhIFNa2b was described as a result of a conformational change accompanied by adoption of amyloid-like properties, indicative for protein misfolding, that was far more immunogenic in vivo than its native counterpart and broke immune tolerance. In addition, Posttranslational modifications such as oxidation, deamidation, and aggregation influence protein immunogenicity $[13,14]$. Specific modifications in formulations and packaging have also been correlated to biopharmaceutical immunogenicity, which for example, has been observed with a specific formulation of EPO that was far more immunogenic than its previous formulation [14]. One of the main problems in formulation development is maintaining protein stability, because chemical modification, adsorption, and most importantly, aggregation phenomena are generally difficult to prevent [18].

$\checkmark$ To increase the stability of the drug product nonhuman sequences are incorporated in the construction of plasmid. These sequences are sometimes detrimental and may cause immunogenicity [1-10].

$\checkmark$ Amino acid substitution is mainly used for the solubilization and stabilization of drug product. This substitution generally changes the molecular structure of the epitope and the degree of glycosylation which can influence immunogenicity and may be involved in .a break in immune tolerance [1-10].

$\checkmark$ Pegylation can reduce the immunogenicity of some proteins although patients produce antibodies to the polyetjylene glycol (PEG) residue adversely affecting efficacy [15].

$\checkmark$ Carbohydrate moieties present upon biopharmaceuticals can elicit the production of $\mathrm{IgE}$ antibodies that can cause serious adverse reactions including anaphylaxis even upon the first treatment exposure. Pre-existing antibodies against galactose$\alpha$-1,3-galactose have been shown to be responsible for IgE- mediated anaphylactic reactions in patients treated with cetuximab [23].

\section{Process related}

There are several process-related impurities, which can also influence the immunogenicity [24]. This includes traces of residual DNA or proteins from the expression system. The protein contaminants from the manufacturing systems can also influence immunogenicity. As discussed earlier, the contaminants from the container-closure that leach from the product can increase the incidence of pure red cell aplasia (PRCA) [11,12,25].

\section{Patient related}

Several patient-related factors, e.g. genetic makeup, age, gender, disease status, concomitant medication, and route of administration, may also be related to antibody response of a particular drug. Concomitant therapy with immunosuppressive drugs can also influence a patient's immune response to a biopharmaceutical [1]. A few risk factors are summarized in the following:

- Route of administration also influence the immune response to a biopharmaceutical. Typically, administration of a protein in a single dose results in the production of low-affinity IgM antibodies, while repeated administration results in the production of high-affinity and high-titer IgG antibodies, which may be neutralizing [2-10].

- As discussed earlier, the duration of treatment can also trigger the immunogenicity.

- The complexity of the humoral response to biopharmaceuticals produces the difficulty in establishing the effect of ADA on drug efficacy [1-10].

\section{Immunogenicity and risk assessment plan}

Risk identification is required for the safety of the drug product as risks may develop several clinical consequences related to safety and efficacy e.g. Anaphylaxis, cytokine release syndrome infusion reactions, non-acute reactions cross-reactivity to endogenous proteins [1-10]. Risk based approach suggests to develop a risk assessment plan [2629]. The plan includes all the above factors were discussed earlier (e.g. product related process related, patient related and other nonclinical related). The output of the assessment will determine the intensity of immunogenicity. A draft plan is shown in Table 1.

\section{Immunogenicity and biosimilar}

The manufacturing and commercialization of these biological drugs are very expensive. Production of biosimilars at the expiry of

\begin{tabular}{|l|l|l|}
\hline Topics & Factors & Content \\
\hline Product related & Intrinsic & Product profile, sequence homology \\
\hline Extrinsic & Process related impurities, Aggregates, Degradation Products, Stability of active ingredients in DP formulation \\
\hline Immunogenicity related clinical risks & & $\begin{array}{l}\text { Cross-reactive Abs, Drug hypersensitivity responses, Abrogation of efficacy due to neutralizing Abs or quick } \\
\text { clearance }\end{array}$ \\
\hline Analytical Methods & $\begin{array}{l}\text { Rationale for choice of methods, PK assay, ADA assay, assessment of cross reactive potential, neutralizing Ab } \\
\text { assay etc. }\end{array}$ \\
\hline Nonclinical & Overview, ADA vs PK/PD, and Other toxicities \\
\hline Clinical & Studies contributing to immunogenicity, ADA responses, ADA vs PK/PD, ADA vs efficacy \\
\hline & & Impact of immunogenicity on overall assessment of benefit and risk \\
\hline
\end{tabular}

Table 1: Risk assessment plan for immunogenicity. 
patents have become necessary in order "to drive down medical costs." Unfortunately, manufacturing of biosimilars are often different from the originator leading to variations in starting raw materials, manufacturing processes, and even in the end products. As a result, such variations may trigger unwanted immunogenicity. Using clinical and bioanalytical data coupled with the data of increase in incidence of adverse events, Chamberlain attempted to identify the clinically meaningful difference in immunogenicity between biosimilar versions of infliximab with a reference product [30]. The result output was selected from Phase III study that compares the efficacy and the safety of the drug product. He grouped the subjects and patients on the basis of ADA titer. The groups with low ADA titer meet the biosimilarity requirement (E.g. 85-120\% bioequivalence).

Recently Kay summarized the presentation on biosimilars at European League against Rheumatism (EULAR) Annual Scientific meeting, held in July 2014 [31]. He indicated that through various clinical studies biosimilar versions of infliximab, etaercept and rituximab continue to show similarity to reference products. Trial design sets a new paradigm for the comparison of biosimilars of low ADA titer with reference products, looking at early time points as a sensitive window in which to look for the equivalence of the two molecules.

\section{Factors Minimizing the Generation of Unwanted Immunity}

Modification of protein is a common technique. It yields the improvement of the properties: like efficacy, stability, specificity, immunogenicity and pharmacokinetics (PK). Such modifications are performed through chemical or post-translation modifications, manipulation of primary structure, and construction of fusion proteins. The most common route to optimization is site-directed mutagenesis [32]. Recently proteins are constructed through rational design methods and the high resolution protein structures are determined and optimized [33,34].

Drug development is performed on the basis of their chemistry manufacturing control (CMC) information and clinical use. Many proteins are poorly expressed and degraded rapidly, whereas the high producer proteins require high levels of solubility as well as retention of functional activity throughout the manufacturing processes [35]. There are several steps of formulation and manufacturing, so that the proteins are exposed to a number of stresses due to multiple steps of formulations and manufacturing. Such stresses may produce unfolded, misfolded or degraded proteins [20-22]. Proteins are re-engineered to yield more robust molecular structure and functional activity so that they are stable under all stresses (e.g. protease exposure, oxidative stress, changes in temperature, $\mathrm{pH}$ and solution conditions) [16-22,25].

One simple stabilization strategy is to replace free cysteine, thereby preventing the formation of unwanted intermolecular or intramolecular disulfide bonds. Cysteine to serine mutations have been introduced successfully into several therapeutic proteins [21,22]. Aggregation can decrease functional activity and bioavailability whereas increase immunogenicity [33]. Several strategies have been applied successfully to reduce protein aggregation and enable soluble expression

- Replacement of unpaired cysteine residues can prevent the formation of unwanted intermolecular disulfide bonds, as described above [1-10].

- Post-translational and chemical modifications (e.g. glycosylation) can also help to prevent aggregation. Substituting exposed nonpolar residues with polar residues can enable soluble expression and improve the solubility of the purified protein [22].

- Altering the net charge and isoelectric point (pI) of a protein can also affect its solubility. For example, a single chain antibody targeting renal cell carcinoma was altered to increase solubility by adding five glutamic acid residues to the $\mathrm{C}$-terminus, thus lowering the $\mathrm{pI}$ from 7.5 to 6.1 [33].

- The PK of a therapeutic protein can be increased more dramatically through fusion to a protein that is known to have a long serum half-life, typically albumin or the $\mathrm{Fc}$ region of antibodies [22].

Pharmacokinetics (PK) measures the protein concentration in serum over time. This is related to improved efficacy and decreased side-effects. It is important to know the route or routes of excretion of drug i.e. kidney filtration or ligand-receptor system. Affinity and specificity modifications are a central component of many therapeutic optimization strategies, and thus receptor-mediated clearance might play an important role in the efficacy of many proteins.

The followings are known to increase PK [1-10,21,22]:

- Polyethylene glycol attachment (PEGylation)

- Glycosylation, or site-specific incorporation of glycosylation through engineering for additional $\mathrm{N}$-linked glycosylation sites

- Fusion to proteins with long serum half-lives, alteration of oligomerization state

\section{- Modulation of receptor-mediated uptake and turnover}

PEGylation is a process of chemical modification of therapeutic proteins. This increases the size of protein as well as PK and reduces immunogenicity and aggregation.

In a straightforward application of molecular size manipulation, proteins covalently fused to themselves often display significantly improved PK profiles [21-22]. The PK of a therapeutic protein can be increased more dramatically through fusion to a protein that is known to have a long serum half-life, typically albumin or the Fc region of antibodies.

Since ADA can complicate interpretation of the toxicity, PK, and PD. Risk based approach to evaluation of immunogenicity of biotherapeutics has become a standard and broadly accepted practice. Detailed strategy used for detection and characterization of anti-drug antibodies are commonly based on the characteristics of the product and treatment [26-28].

\section{Immunogenicity and Risk Mitigation Plan}

Risk control is to reduce the risk to an acceptable level. Risk reduction might include actions taken to mitigate the severity and probability of adverse reaction. For risk control a procedure is required to develop which will provide the strategies for the risk assessment and risk mitigation including addressing the issues of the biochemical nature of product development, the extent of similar known risks for related marketed products, and the availability of biomarkers or other assays that may help to quantify the risks. The following may also provide a relevant risk mitigation strategy:

$\checkmark \quad$ A specific and sensitive (including drug tolerant) assays for evaluating antibodies to therapeutic protein.

$\checkmark$ Product-specific antibody sampling plan based on the phases of 
development (early vs. late), providing information on human immunogenicity with clinical experience.

$\checkmark$ Development of dosing and dose escalation studies using time intervals with great cautions.

$\checkmark$ Careful evaluation of all adverse events potentially mediated by an immune response.

Further it provides recommendations for immunogenicity risk mitigation in the clinical phase of development of therapeutic proteins and patient specific factors that affect immunogenicity through route of administration, dose, and frequency of administration, and status of immune tolerance to endogenous protein. A draft of risk controlling plan is shown in Table 2.

\section{Regulatory Guidance}

Immunogenicity is an important safety concern for clinical drug development process. So the Committee for medicinal products for human use (CHMP) published guidance regarding Immunogenicity assessment on April 2008 [19]. Since this is a general guideline e.g 85-12 e.g.e, and does not deal with specific products, so European Medicine Agency (EMA) published guidance related to monoclonal antibody on December, 2012 [35]. This guideline aimed at development and systematic evaluation of an unwanted immune repose against a therapeutic protein. It considers the major quality and clinical aspects of the issues and risk related to the development of an unwanted immune response to a particular $\mathrm{mAb}$ in a particular clinical indication. Consequently EMA published another guideline effective on the same date related to nonclinical and clinical issues [36]. FDA also issued guidance on Assay Development on December, 2009 [37]. Recently FDA issued guidance on Immunogenicity Assessment for Therapeutic Protein Products [38]. This draft guidance is a risk based approach in both the preclinical and clinical phases of product development of therapeutic proteins for evaluation of immunogenicity with an emphasis of extending to post marketing setting [39].

\section{Proposal for Remedies}

As described earlier, the drug development processes for biosimilar product are complex starting from CMC information to clinical developments [25]. Moreover, Formulation, manufacturing and various other chemistry manufacturing control (CMC) information of the biosimilar are different from the originator. . Recreate highly similar molecule with the branded drug, formulate, and manufacturing processes contribute some extrinsic and intrinsic factors, which led to an adverse event undesired immunogenicity. To control such an event well designed formulation coupled with good manufacturing scheme are developing. Several of these biosimilar drug products are contaminated with various impurities (product, process or patient related). But it is required to develop purification scheme so that the biosimilar drug products will be purified to homogeneity or near homogeneity preserving functional activities with no toxicological issues. The impurities protein content in near homogeneous drug product will be negligible or minimum. Such a low content of protein impurity may not raise clinical issues. With more advancement, research and development may solve these issues in the near future. This may reduce multiple clinical studies and open up easier regulatory pathway for biosimilar approval.

\section{Conclusion}

Biosimilar field promises some new and exciting opportunities. The patent of a good number of branded products will be expired (Table 3) and these products are now in development of the economical version of branded drugs designated as biosimilars [40]. It is expected that the

\begin{tabular}{|c|c|}
\hline Elements & Description \\
\hline Quality & $\begin{array}{l}\text { - Manage process changes } \\
\text { - Sensitivity of analytical methods to allow determination of changes to product (aggregation, glycosylation etc.) } \\
\text { Formulation and impact of changes }\end{array}$ \\
\hline Bioanalytical Assay & $\begin{array}{l}\text { - } \quad \text { Assay format and assay platform } \\
\text { - } \quad \text { Sensitivity, drug tolerance, assay range } \\
\text { Positive controls }\end{array}$ \\
\hline Nonclinical/Clinical & $\begin{array}{l}\text { - } \quad \text { Sampling plan } \\
\text { - Studies in clinical development plan to assess specific aspects of immunogenicity } \\
\text { - } \quad \text { Safety monitoring assessment of immunogenicity on efficacy } \\
\text { Reporting/analysis plan }\end{array}$ \\
\hline
\end{tabular}

Table 2: Plan for controlling immunogenicity.

\begin{tabular}{|c|c|c|}
\hline Biological Products & Indications & Expected Expiry date \\
\hline Adalimuzumab (Humara) & Rhematoid arthritis, psoriatic arthritis, ankylosing spondylitis, Crohn's disease & $\begin{array}{l}\text { 2018(EU) } \\
2016(U S)\end{array}$ \\
\hline Bevacizumab (Avastin) & Metastatic colorectal cancer, HER2 negative breast cancer & $\begin{array}{l}2022 \text { (EU) } \\
2019 \text { (US) }\end{array}$ \\
\hline Cetuximab( Erbitux) & EGFR expressing metastatic colorectal cancer, squamous cell carcinoma of the head and neck & $\begin{array}{l}\text { 2014(EU) } \\
2016(U S)\end{array}$ \\
\hline Etanercept (Enbrel) & Rheumatoid arthritis, ankylosing spondylitis, plaque psoriasis & $\begin{array}{l}\text { 2015(EU) } \\
2013 \text { (US) }\end{array}$ \\
\hline Infliximab (Remicad) & Crohn's disease, ulcerative colitis, rheumatoid arthritis, ankylosing spondylitis, psoriatic arthritis & $\begin{array}{l}\text { 2014(EU) } \\
\text { 2018(US) }\end{array}$ \\
\hline Palivizumab (Synagis) & Respiratory disease caused by respiratory syncytial virus & $\begin{array}{l}\text { 2015(EU) } \\
2015(U S)\end{array}$ \\
\hline Retuximab(Rituxan) & CD-20-positive non-Hodgkins lymphoma,chronic lymphocytic leukemia, rheumatoid arthritis & $\begin{array}{l}\text { 2013(EU) } \\
2018(U S)\end{array}$ \\
\hline Trastuzumab (Herceptin) & HER2-positive breast cancer, metastatic breast cancer that overexpresses HER2 & $\begin{array}{l}2014 \text { (EU) } \\
2019 \text { (US) }\end{array}$ \\
\hline
\end{tabular}

Table 3: Expected patent Expiry of some branded products. 
Citation: Bandyopadhyay A (2015) Complexities of Protein Therapeutics and Immunogenicity. J Bioanal Biomed 7: 070-074. doi:10.4172/1948593X.1000126

marketing applications of these biosimilars will be submitted in next several years. Unfortunately, biosimilar manufacturing is often different from the brand name drug due to variation in manufacturing processes. As a result, such variations may trigger unwanted immunogenicity. Assessment of such immunogenicity is an important component of drug safety evaluation. Risk based approach, like branded drug, is more likely be required for drug development of biosimilar therapeutic proteins in both pre approval and post approval phases. Risk based approach considers both probability of induction of immune response and expected clinical consequences. Risk assessment plan may provide strategies for risk mitigation.

\section{Acknowledgement}

I am grateful to Dr. Boris Gorovits $\mathrm{PhD}$ for his kind review and helpful suggestions for the modification of the manuscript.

\section{References}

1. Tovey MG, Lallemand C (2011) Immunogenicity and other problems associated with the use of biopharmaceuticals. Ther Adv Drug Saf 2: 113-128.

2. Bachmann MF, Zinkernagel RM (1997) Neutralizing antiviral B cell responses. Annu Rev Immunol 15: 235-270.

3. Rosenberg AS (2006) Effects of protein aggregates: an immunologic perspective. AAPS J 8: E501-507.

4. Ponce R, Abad L, Amaravadi L, Gelzleichter T, Gore E, et al (2009) Immunogenicity of biologically-derived therapeutics: Assessment and interpretation of nonclinical safety studies Regulatory Toxicology and Pharmacology 54: 164-182.

5. Rosenberg AS (2006) Effects of protein aggregates: An immunologic perspective. AAPS J 8: E501-E507.

6. Rosenberg AS, Worobec A (2004) A risk-based approach to immunogenicity concerns of therapeutic protein products-Part 1 -considering consequences of the immune response to a protein. Biopharm Int 17: 22-26.

7. Rosenberg AS, Worobec A (2004) A risk-based approach to immunogenicity concerns of therapeutic protein products-Part 2-considering host-specific and product-specific factors impacting immunogenicity. Biopharm Int 17: 34-42.

8. Rosenberg AS, Worobec A (2005) A risk-based approach to immunogenicity concerns of therapeutic protein products-Part 3-effects of manufacturing changes in immunogenicity and the utility of animal immunogenicity studies. Biopharm Int 18: 32-36

9. De Groot AS, Scott DW (2007) Immunogenicity of protein therapeutics. Trends Immunol 28: 482-490.

10. Murphy K (2011) The Humoral Immune Response, in Janeway's Immunobiology. Garland Science Publishing, New York pp: 367-408.

11. Test ST, Mitsuyoshi J, Connolly CC, Lucas AH (2001) Increased immunogenecity and induction of class switching by conjugation of complement C3d to pneumococcal serotype 14 capsular polysaccharide infect. Immunol 69: 30313040 .

12. Schellekens $\mathrm{H} 1$ (2005) Immunologic mechanisms of EPO-associated pure red cell aplasia. Best Pract Res Clin Haematol 18: 473-480.

13. Hay M, Rosenthal J, Thomas D, Craig J, Bio/Biomed tracker clinical trial success rates study, BIO CEO\& Investor Conference, BIO February 15th, 2011

14. Chirino AJ, Ary ML, Marshall SA (2004) Minimizing the immunogenicity of protein therapeutics. Drug Discov Today 9: 82-90.

15. De Groot AS, Martin W (2009) Reducing risk, improving outcomes: bioengineering less immunogenic protein therapeutics. Clin Immunol 131: 189201.

16. Moore WV, Leppert $P$ (1980) Role of aggregated human growth hormone (hGH) in development of antibodies to hGH. J Clin Endocrinol Metab 51: 691-697.

17. Braun A, Kwee L, Labow MA, Alsenz J (1997) Protein aggregates seem to play a key role among the parameters influencing the antigenicity of interferon alpha (IFN-alpha) in normal and transgenic mice. Pharm Res 14: 1472-1478.

18. Mire-Sluis A, Cherney B, Madsen R, Polozova A, Rosenbeg A, et al. (2011) Analysis and Immunogenic Potential of Aggregates and Particles BioProcess Int 9: 38-43.
19. EMA (2007) Guideline on Immunogenicity Assessment of BiotechnologyDerived Therapeutic Proteins. EMA, London, UK.

20. Wang W (2005) Protein aggregation and its inhibition in biopharmaceutics. Int J Pharm 289: 1-30.

21. Hermeling S, Crommelin DJ, Schellekens H, Jiskoot W (2004) Structureimmunogenicity relationships of therapeutic proteins. Pharm Res 21: 897-903.

22. Frokjaer S, Otzen DE (2005) Protein drug stability: a formulation challenge. Nat Rev Drug Discov 4: 298-306.

23. Chung CH, Mirakhur B, Chan E, Le QT, Berlin J, et al. (2008) Cetuximabinduced anaphylaxis and IgE specific for galactose-alpha-3-galactose. $\mathrm{N}$ Engl J Med 358: 1109-1117.

24. Wadhwaa M, Birda C, Dilgera P, Gaines-Dasb R, Thorpea R (2003) Strategies for detection,measurement and characterization of unwanted antibodies induced by therapeutic biological. J Immunol Methods 278: 1-17.

25. Bandyopadhyay A (2013) Complexities of Biosimilar Product. J Bioanal Biomed 5: 118-121.

26. Shankar G, Devanarayan V, Amaravadi L, Barrett YC, Bowsher R, et al. (2008) Recommendations for the validation of immunoassays used for detection of host antibodies against biotechnology products. J Pharm Biomed Anal 48: 1267-1281.

27. Shankar G, Pendley C, Stein KE (2007) A risk-based bioanalytical strategy for the assessment of antibody immune responses against biological drugs. Nat Biotechnol 25: 555-561.

28. Gorovits B, Wakshull E, Pillutla R, Xu Y, Manning MS, et al. (2014) Recommendations for the characterization of immunogenicity response to multiple domain biotherapeutics. J Immunol Methods 408: 1-12.

29. Chamberlain $P$ (2011) Addressing immunogenicity-related risks in an integrated manner, Regulatory Affairs.

30. Chamerlin P (2013) Assessing Immunogenicity of biosimilar therapeutic monoclonal antibodies: regulatory and bioanalytical considerations Bioanalysis 5: 561-574.

31. Kay J (2014) Biosimilars: As Good as the Originals? Medscape Rheumatology.

32. Zakrzewska M, Krowarsch D, Wiedlocha A, Olsnes S, Otlewski J (2005) Highly stable mutants of human fibroblast growth factor-1 exhibit prolonged biological action. J Mol Biol 352: 860-875.

33. Laroche Y, Heymans S, Capaert S, De Cock F, Demarsin E, et al. (2000) Recombinant staphylokinase variants with reduced antigenicity due to elimination of B-lymphocyte epitopes. Blood 96: 1425-1432.

34. Koren E, Smith HW, Shores E, Shankar G, Finco-Kent D, et al. (2008) Recommendations on risk-based strategies for detection and characterization of antibodies against biotechnology products. J Immunological methods 333 $1-9$

35. EMA (2012) Guideline on Immunogenicity Assessment of Monoclona Antibodies Intended for In Vivo Clinical Use. CHMP, London, UK.

36. EMA (2007) Guideline on Immunogenicity Assessment of Monoclonal Antibodies Intended for In Vivo Clinical Use. EMA, London, UK.

37. US FDA (2009) Guidance for Industry: Assay Development for Immunogenicity Testing of Therapeutic Proteins. CDER/CBER.

38. US FDA (2013) Guidance for Industry: Immunogenicity Assessment for Therapeutic Protein Products (Draft). CDER/CBER, USA.

39. Parenky A, Myler H, Amaravadi L, Bechtold-Peters K, Rosenberg A, et al (2014) New FDA draft guidance on immunogenicity. The AAPS Journal 16: 499-503.

40. GaBI Online - Generics and Biosimilars Initiative (2014) US\$67 billion worth of biosimilar patents expiring before 2020 . 